\title{
Vicissitude of Curetted Adenoid Vegetations
}

\author{
Susumu Mukai \\ Otorhinolaryngology, Mukai Clinic, Yamato, Kanagawa, Japan. \\ Email: s-mukai@da2.so-net.ne.jp \\ Received January 23 ${ }^{\text {rd }}, 2013$; revised March 20 ${ }^{\text {th }}, 2013$; accepted April 28 ${ }^{\text {th }}, 2013$ \\ Copyright (C) 2013 Susumu Mukai. This is an open access article distributed under the Creative Commons Attribution License, which \\ permits unrestricted use, distribution, and reproduction in any medium, provided the original work is properly cited.
}

\begin{abstract}
Weights of curetted adenoid were measured and were compared with both weights of tonsils and the rate of adenoidectomy among the tonsillectomized cases. This study included 603 patients whose adenoids were curetted during the 11-year period. $90 \%$ of patients were 2 to 9 years old. The rate of curetted adenoid vegetation among the tonsillectomized cases was $80 \%$ among patients from 1 to 6 years old and $70 \%$ among patients of 7 and 8 years old. The rate remarkably decreased from 9 years of age. The average weight of the curetted adenoids in each age group ranged from $0.7 \mathrm{~g}$ to $1.9 \mathrm{~g}$. There was no statistical correlation in the distribution of the average weight of the curetted adenoids between males and females as well as between the weight of the tonsils and the weight of the curetted adenoids. A hypothesis on the cause of adenoid hypertrophy was presented in this study.
\end{abstract}

Keywords: Adenoid; Choanae; Sunusitis; Choanal Development; Ankyloglossia with Deviation of the Epiglottis and Larynx (ADEL)

\section{Introduction}

Over twenty years have passed since the identification of ankyloglossia with deviation of the epiglottis and larynx (ADEL). The anatomical condition of ADEL is as follows: the tongue is in the forward position, both of the frenulum lingua are attached to the tongue and/or there is no frenulum, and the epiglottis and the larynx are elevated and forward. This condition increases airway resistance, thereby reducing respiratory parameters such as vital capacity (VC) and forced expiratory volume in 1 second (1\%FEV) [1-7]

Respiratory distress in babies is mainly caused by ADEL [8]. There are many signs and symptoms of the respiratory distress caused by ADEL. Some of them are sleep apnea, harsh respiratory sounds, thumb thucking, suckling problems, colic cry, cold extremities, swollen abdomen, protruded navel, cutis marmorata and eczema. They lack eye contact. They are afraid of strangers. They have a stiff body and other symptoms [1,8-11]. These symptoms were considered to have unknown etiology $[12,13]$. Individuals with ADEL also have underdeveloped maxillo-mandibular bones, malaligned teeth, high tongue positions, etc. [14].

Not only the tongue and the larynx but also the respiratory system had evolved from the muscles of gills of fish. The transformation began from the Devonian Period, about 307 million years ago, and fish inhabited the land. The tongue and the larynx of mammals evolved from the 2nd branchial arch $[15,16]$. Thus, the condition of ADEL originates from mammalian phylogeny. "Organs not in all cases absolutely perfect (C. Darwin)" [17]. It is not too much to say that ADEL was loaded on the lives of humans like the basso continuo of baroque music.

Surgical correction of the glosso-larynx (CGL) and expansion of the vestibular oris (EVO) greatly ameliorate these symptoms [3,6,7,12,18].

Besides ADEL, during childhood, adenoid vegetations and tonsillar hypertrophy increase upper airway resistance. These conditions aggravate both respiration and sleep.

Both adenoid vegetations and tonsillar hypertrophy cause upper airway narrowing. Noguchi et al. [19] reported that the majority of respiratory sleep disorders in infants is caused by adenotonsillar hypertrophy. In addition, Miyazaki et al. [20] reported that respiratory sleep disorders in infants result in not only daytime somnolence and ill-defined decrease in learning abilities, but also thoracic deformities and corpulmonale. Adenotonsillar hypertrophy may even cause sudden death in infants. For infants with adenotonsillar hypertrophy, they recommend that adenotonsillectomy be performed. It can be said that adenoid vegetations are infant-specific dis- 
orders [19,21-23]. However, only a few reports on adenoid vegetations and tonsils referred to ADEL. Knowledge about ADEL is required to study respiration and sleep.

Over the past ten years, the authors weighed the excised tonsils of patients who underwent tonsillectomy at our clinic. The results revealed that tonsils increase in weight with growth of the individual. When the surgical procedure was adeno-tonsillectomy, the weight of both the tonsils and curetted adenoid was measured.

The authors discuss the weight of the curetted adenoid and adenoid vegetations related to choanal development, and present a hypothesis on the cause of adenoid hypertrophy in this study.

\section{Cases and Methods}

\subsection{Cases and Study Period}

This study included patients who were diagnosed with adenotonsillar hypertrophy and whose adenoids were curretted at the Otorhinolaryngology, Mukai Clinic during the 11-year period between June 27, 2000 and June 14, 2011. This prospective study was approved by the Human Subjects Committee of our clinic. Informed consent was obtained from each patient or guardian.

The adenoids were observed by a laryngo-fiberscope via the nose. When the adenoids obstructed the choanae and they protruded into the nasal cavity, the diagnosis of adenoid hypertrophy was made (Figure 1).

The adenoidectomies and tonsillectomies were performed under general anesthesia except in the two adult cases.

\subsection{Adenoidectomy}

Following is a description of the adenoidectomy procedure performed in children under 15 years of age. As the adenoids or pharyngeal tonsils are situated uppermost of the epipharynx or nasopharynx, it is impossible to see

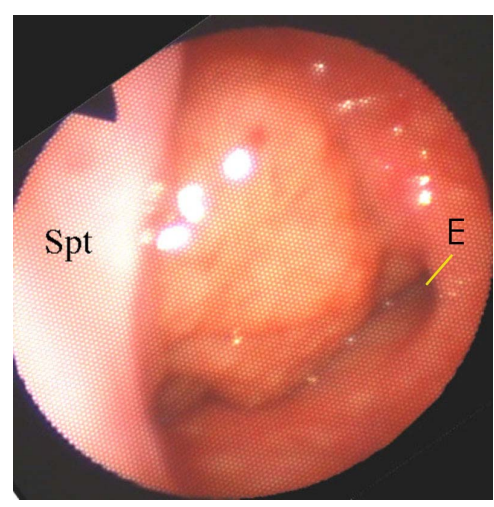

Figure 1. Fiberscopic view of adenoid hypertrophy via the left nasal cavity (The adenoids protrude into the nasal cavity. Spt, nasal septum; E, ostium of left Eustachian tube). them directly by the naked eyes. Under general anesthesia, the mouth was opened by a Crowe-Davis mouth gag and the head hung down in the neck-extended position. Nélaton's catheters were passed through from the nose to the mouth, the soft palate was held upward by pulling the Nélaton's catheters, and both ends were fixed by Péan's forceps. Using these procedures, the adenoids, choanal nasal septum and inferior conchae could be observed by a laryngeal mirror that was inserted via the oral cavity.

Observing the mirror, the blade of Beckmann-Thompson's type adenoid curette (length of the blade, $19 \mathrm{~mm}$ ) was inserted between the base of the nasal septum and the adenoids (Figure 2). Then, the adenoids were curetted without stopping.

In contrast, in adults, the adenoids were blindly curetted in the face down position under local anesthesia.

\subsection{Measurement of the Curetted Adenoids}

The adenoids were weighed on a digital scale (YUYAMA CS-300S, Yuyama Ltd., Osaka, Japan; minimum weight $0.01 \mathrm{~g}$ ) immediately after they were curetted. The weights of the adenoids were expressed in grams to one decimal point. The curetted adenoids were subjected to histological examination.

StatView and Excel were employed for statistical analyses.

\section{Results}

\section{Cases}

This study included 603 patients (male 414, female 189) whose adenoids were curetted during the 11-year period of this study. They ranged in age from 1 to 38 years old. Ninety percent of the patients were 2 to 9 years old. There were two adult cases, who were 18 and 38 years old (Figure 3).

The rate of curetted adenoid vegetation among the tonsillectomized cases was $80 \%$ among patients from 1 to 6 years old and $70 \%$ among patients of 7 and 8 years of age. The rate remarkably decreased from 9 years of age. The two adult cases of adenoid hypertrophy were male (Figure 4).

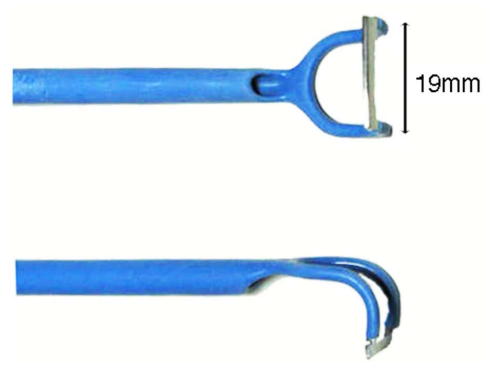

Figure 2. Beckmann-Tompson's type adenoid curette (Ellman Japan Ltd.). Length of the blade is $19 \mathrm{~mm}$. 


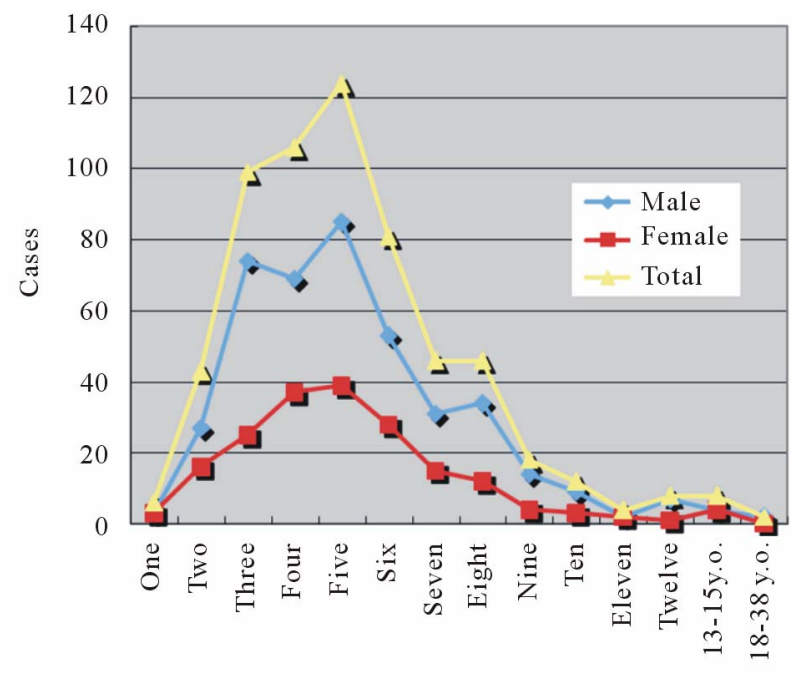

Age group (y.o.)

Figure 3. Age distributions of the adenoids curetted cases.

Rate of curetted adenoid vegetation cases in tonsillectomized cases

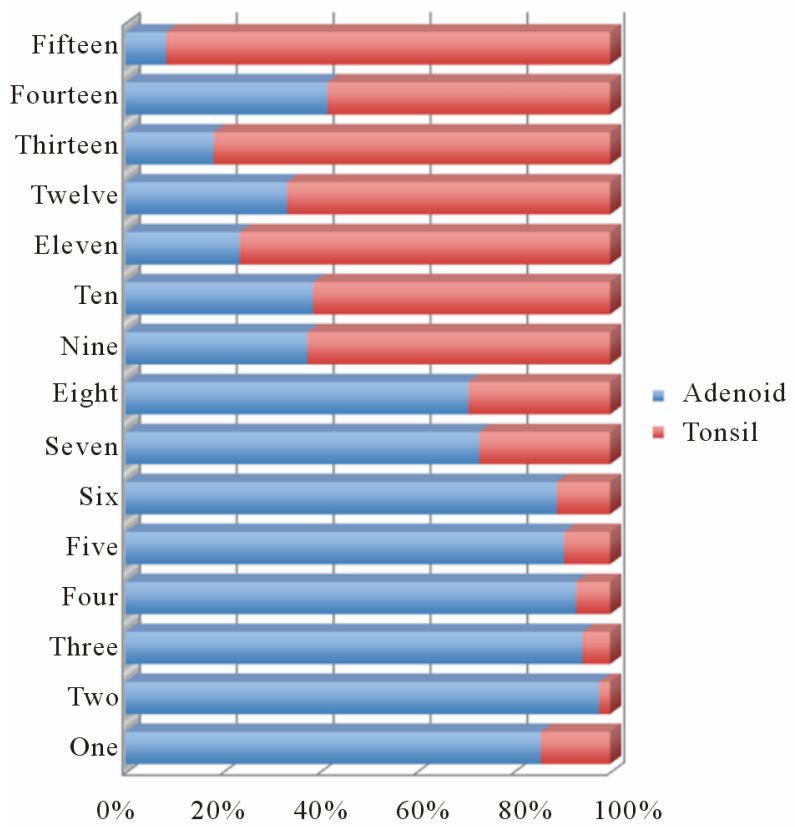

Figure 4. Rate of curetted adenoid vegetation among the tonsillectomized.

The average weight of the curetted adenoids in each age group ranged from $0.7 \mathrm{~g}$ to $1.9 \mathrm{~g}$ (Figure 5). The maximum weight of the adenoids among males and females was $5.1 \mathrm{~g}$ in a 3-year-old boy and $4.2 \mathrm{~g}$ in a 5-yearold girl. There was no statistical correlation in the distribution of the average weight of the curetted adenoids between males and females. In the two adults, the curetted adenoids weighed $1.5 \mathrm{~g}$ and $1.3 \mathrm{~g}$ in male individuals aged 18 and 38 years old.

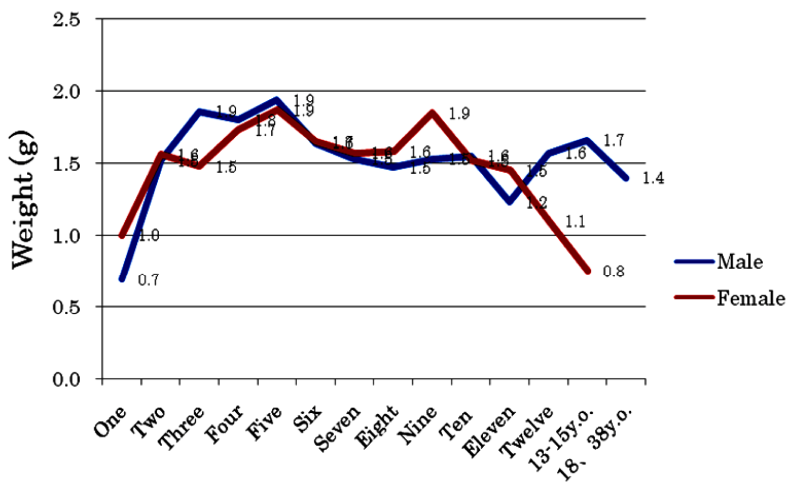

Age group (y.o.)

Figure 5. Average weight distribution of the curetted adenoid by age group and gender.

In addition, there was no correlation between the weight of the tonsils and the weight of the curetted adenoids. Cases that had heavy tonsils did not always have heavy curetted adenoids and vice versa.

\section{Discussion}

The adenoids, or pharyngeal tonsils, develop from the second branchial arch. They are already mature in the sixmonth embryo [21,24]. There are differences between reports about the maximum volume of the adenoids. One study reported that the maximum weight was seen in individuals of 4 or 5 years old [25]. In another study, the maximum weight was seen in individuals of 6 or 7 years old [21]. The volume of the adenoids decreases after 11 years of age.

In previous studies, simple X-ray photographs were routinely employed to diagnose adenoid hypertrophy [2628] (Figure 6). In $X$-ray images, one can observe sections and sagittal expansion of the adenoids. However, $\mathrm{X}$-rays show merely instantaneous and fixed figures. Moreover, both the children and their helpers are exposed to the radiation.

Adenoid hypertrophy was diagnosed by a laryngo-fiberscope via the nose in all cases in this study. An advantage of using the laryngo-fiberscope is that one can observe not only the adenoids but also the adjacent tubal tonsils and the ostium of the Eustachian tube. In addition, the condition of the nasal mucous membranes, nasal discharges and opening of the choanae can be observed. The observations by fiberscope were recorded on a digital video casette recorder (DVCAM; DSR-30, SONY Co., Tokyo, Japan). After making observations while playing the recorded DVCAM, the condition of the adeno-tonsils as well as choanal opening, nasal cavities, nasal discharges and tubal tonsil was shown to their families. They can comprehend the condition and need for surgery. 


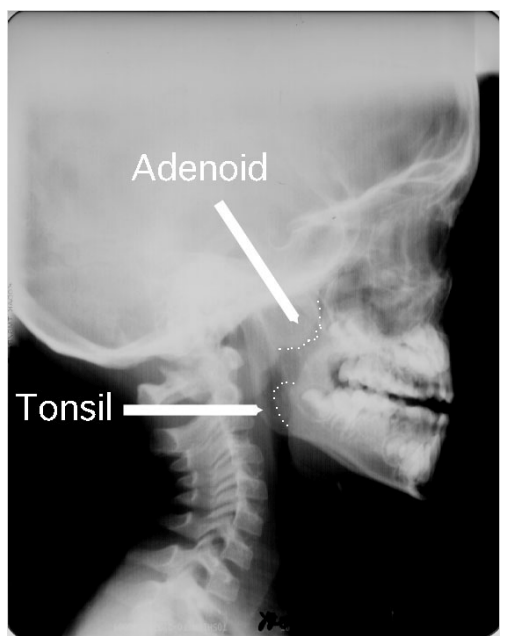

Figure 6. Simple X-ray photograph of the adenoid. Sagittal expansion of the adenoid is observable by the photo. The patient's mouth is usually open due to nasal obstruction by hypertrophied adenoid. Half of tonsil protruded into the hypopharynx.

Nasal obstruction by adenoid vegetations occurs depending on the apertures of the choanae. The apertures of the choanae in newborn babies are semicircular and very narrow. At that time, the adenoids are hardly observable in the choanae. The aperture of the choanae expands mainly vertically with the growth of the respiratory cranium. The aperture of the choanae becomes round at one to two years of age. The adenoids develop during this time. The adenoids protrude into the nasal cavities from the ceiling of the epipharynx in proportion to the choanal widening. At about seven years of age, the apertures of the choanae are almost as wide as those in adults $[29,30]$. The adenoids begin to retract from the choanae to the epipharynx. The volume of the adenoids is relatively small compared with the widened choanal aperture (Figures 7-9).

In this study, we found that the adenoids develop rapidly at about two years of age. Their volumes were maximal from four to six years of age. After seven years of age, they begin to shrink rapidly. The rate of adenotonsillectomy among the tonsilletomized cases dropped sharply in patients over 9 years old. Adenoidectomy was rarely performed over the age of 16 years.

There was little difference in the weight of adenoids that had been curetted from children aged 2 years old to 9 years old. Two reasons are suggested for this. The first reason is that there is no difference in the size of the adenoids of individuals from 2 to 9 years of age. The second reason is that the curetted weight depends on the length of the blade. It was reported that a curette with a length of 17 to $21 \mathrm{~mm}$ is sufficient for adenoidectomy [24]. In this study, a Beckmann-Thompson's type adenoid curette with a $19 \mathrm{~mm}$ blade was employed. The length of the cu-

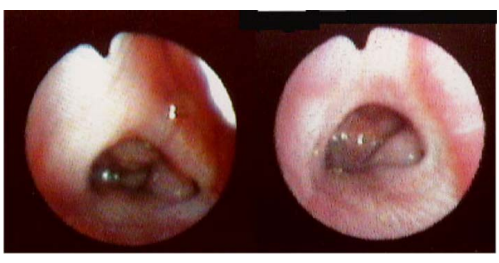

$2 \mathrm{~m}$

$4 \mathrm{~m}$

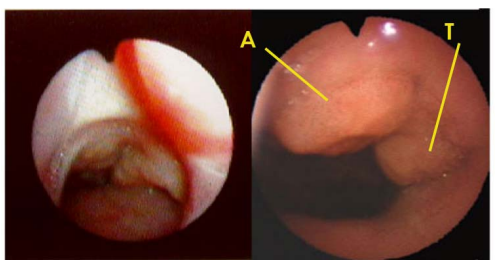

$1 y$

$4 y$

Figure 7. Opening of choanae ( $2 \mathrm{~m}$ : 2 months old (mo), $4 \mathrm{~m}$ : 4 mo, 1 y: 1 yo, 2 y: 2 yo, A: adenoid, T: tubal tonsil). Adenoid (A) and tubal tonsil (T) are clearly visible at 2 years by laryngo-fiberscope via the nose.

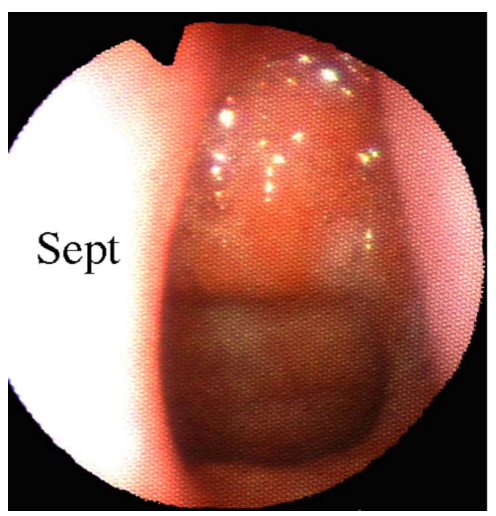

Figure 8. Choanal opening of a 7 years old boy, (The opening of choanae is almost as large as adults. Adenoid is visible above the nasopharynx. Spt: nasal septum).

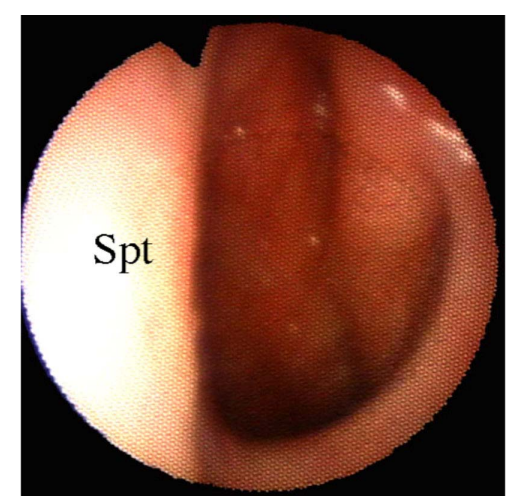

Figure 9. Choanal opening in an adult (Spt: nasal septum). The adenoid is no longer visible. Torus tubarius can be clearly seen on the right side.

rette is suitable for curetting adenoid hypertrophy. There is a possibility that a $19 \mathrm{~mm}$ blade will constantly curette a certain amount of adenoids. 
The weight of curetted adenoid vegetations of adults was less than that of infants. Adenoidectomy in adults is performed under local anesthesia without observing the adenoids. This may have been the reason why the curetted adenoids of adults were lighter than those of the infants.

Although histopathologically adenoid vegetation and tonsillar hypertrophy show the same histology, the two organs develop differently. Adenoid vegetations shrink quickly after 9 years of age and they are hardly observable in the epipharynx of adults (Figure 8). In contrast, the tonsils increase in size with aging. The tonsils have capsules, while the adenoids do not. These differences suggest that the two organs are physiologically different.

By our clinical experiences, children with adenoid vegetations have sinusitis. Infections with sinusitis start before the development of adenoid vegetations. Even at the first month of age, these babies already have sinusitis.

Purulent rhinorrhea due to sinusitis runs down constantly towards the choanae. The purulent rhinorrhea might stimulate the adenoids directly since the choanal exit of the children is very narrow. When the apertures of the choanae grow to a vertical ellipse at around 7 years old, purulent rhinorrhea drains into the oropharynx to the hypopharynx. There might be no more antigenic stimulations to the adenoids in these conditions. Accordingly, the adenoid vegetations might shrink gradually.

The authors hypothesize that the adenoid vegetations are caused by constant stimulation by antigenic rhinorrhea due to sinusitis. The antigenic rhinorrhea stays in the nasal cavities due to the adenoid vegetations. This retention of the antigenic rhinorrhea aggravates both the sinusitis and adenoid vegetations. Sinusitis and adenoid vegetations form a vicious cycle. Actually, after adenoidectomy, the choanae are widened, rhinorhea runs down directly to the hypopharynx, and their sinusitis is promptly relieved.

\section{REFERENCES}

[1] S. Mukai, C. Mukai and K. Asaoka, "Congenital Ankyloglossia with Deviation of the Epiglottis and Larynx," Annals of Otolaryngology, Vol. 100, No. S153, 1991, pp. $1-20$.

[2] S. Mukai, C. Mukai and K. Asaoka, "Congenital Ankyloglossia with Deviation of the Epiglottis and Larynx: Symptoms and Respiratory Function in Adult," Annals of Otolaryngology, Vol. 102, No. 102, 1993, pp. 620-624.

[3] S. Mukai and M. Nitta, "Correction of the Glosso-Larynx (CGL) and Resultant Positional Changes of the Hyoid Bone and Cranium,” Acta Otolaryngologica (Sweden), Vol. 122, 2002, pp. 644-650.

doi:10.1080/000164802320396330

[4] S. Mukai and M. Nitta, "Z-Pharyngoplasty for Sleep Disorder and Rhonchopathy," Acta Otolaryngologica (Sweden), Vol. 122, 2002, pp. 524-530.

\section{doi:10.1080/00016480260092345}

[5] S. Mukai and M. Nitta, "Expansion of the Vestibular Oris (EVO)," Annals of Ankyloglossia with Deviation of the Epiglottis and Larynx, Vol. 12, 2004, pp. 1-9 (in Japanese).

[6] S. Mukai, "Decrease of Nasal Ariflow Registance by Expansion of the Vestibular Oris," Annals of Ankyloglossia with Deviation of the Epiglottis and Larynx, Vol. 15, 2009, pp. 16-20 (in Japanese).

[7] S. Mukai and I. Yamamoto, "Patial Genioglossectomy Leading to an Increase in Respiratory Rate-Surgery for Ankyloglossia with Deviation of the Epiglottis and Larynx," Annals of Ankyloglossia with Deviation of the Epiglottis and Larynx, Vol. 16, 2010, pp. 25-31.

[8] S. Mukai, "Ankuyloglossia with Deviation of the Epiglottis and Larynx (ADEL)," Annals of Ankyloglossia with Deviation of the Epiglottis and Larynx, Vol. 8, 1998, pp. 1-53 (in Japanese).

[9] S. Mukai, C. Mukai, K. Asaoka and S. Nagasugi, "Digit Sucking,” Lancet, Vol. 339, No. 8808, 1992, pp. 15451546. doi:10.1016/0140-6736(92)91316-Z

[10] S. Mukai, C. Mukai, K. Asaoka, S. Nagasugi and M. Ogiyama, "Near Miss for SIDS Seen in Infants Who Have Ankyloglossia with Deviation of the Epiglottis and Larynx," Annals of the Ankyloglossia with Deviation of the Epiglottis and Larynx, Vol. 3, 1993, pp. 33-45 (in Japanese with English Abstract).

[11] H. Suzuki and M. Nakaji, "Relationship between Babies with Ankyloglossia and Disturbance of Their Mother's Breast," Annals of Ankyloglossia with Deviation of the Epiglottis and Larynx, Vol. 3, 1993, pp. 74-84 (In Japanese).

[12] S. Mukai, C. Mukai, K. Asaoka, S. Nagasugi and P. Djupesland, "Prevention of SIDS-Correction of Ankyloglossia with Deviation of the Epiglottis and Larynx," Third SIDS International Conference, Stavanger, 1994, p. 144.

[13] S. Mukai, C. Mukai, K. Asaoka, S. Nagasugi and P. Djupesland, "Subjective and Objective Evaluation of Crying before and after the Correction of Ankyloglossia with Deviation of the Epiglottis and Larynx,” Third SIDS International Conference, Stavanger, 1994, p. 179.

[14] S. Mukai, "New Conseption about Occulusion-View from Ankyloglossia with Deviation of the Epiglottis and Larynx (ADEL)," Japanse Orthodontic Society of General Practitioner, Vol. 22, 2011, pp. 16-17 (in Japanese).

[15] A. S. Romer and T. S. Parsons, "The Vertebrate Body," 5th Edition, W. B. Saunders Co., Philadelphia, 1977, pp. 324-372.

[16] J. A. Clack, "Gaining Ground: The Water to Land Adventure,” Kodansha, Ltd., Tokyo, 2000, pp. 31-290 (in Japanese).

[17] C. D. Darwin, “The Origin of Species,” 6th Edition, New York University Press, New York, 1876, pp. 133-167.

[18] S. Mukai, "Expansion of the Vestibular Oris (EVO)Esthetic Facial Changes and Expansion of the Nasal Cavity," Annals of the Ankyloglossia with Deviation of the Epiglottis and Larynx, Vol. 16, 2010, pp. 32-41. 
[19] K. Noguchi, K. Sato, K. Suganuma, et al., "Sleep Breathing Disorder in Children: Correlation with Adenoid and Palatine Tonsil Hypertrophy," Journal of the Aichi Medical University Association, Vol. 33, 2005, pp. 71-74 (Japanese with English Abstract).

[20] S. Miyazaki, Y. Itasaka, K. Yamakawa, M. Okawa and K. Togawa, "Respiratory Disturbance during Sleep Due to Adenoid-Tonsillar Hypertrophy," American Journal of Otolaryngology, Vol. 10, No. 2, 1989, pp. 143-149. doi:10.1016/0196-0709(89)90138-5

[21] S. E. Brietzeke and D. Gallagher, "The Effectiveness of Tonsillectomy and Adenoidectomy in the Treatment of Pediatric Obstructive Sleep Apnea/Hypopnea Syndrome: A Meta-Analysis," Otolaryngology-Head and Neck Surgery, Vol. 134, No. 6, 2006, pp. 979-984. doi:10.1016/j.otohns.2006.02.033

[22] X. Zhang, Y. Li, F. Zhou, et al., "Comparison of Polygraphic Parameters in Children with Adenotonsillar Hypertrophy with vs without Obstrructive Sleep Apnea," Archives of Otolaryngology — Head and Neck Surgery, Vol. 133, 2007, pp. 122-126. doi:10.1001/archotol.133.2.122

[23] M. Bitar, G. Birjawi, M. Youssef and N. Fuleihan, "How Frequent Is Adenoid Obstruction? Impact on the Diagnostic Approach,” Pediatrics International, Vol. 51, 2009, pp. 478-783. doi:10.1111/j.1442-200X.2008.02787.X

[24] H. F. Shaalan, "What Is the Right Size of the Adenoid
Curette?” The Journal of Laryngology \& Otology, Vol. 117 , No. 10 , 2003, pp. $796-800$. doi:10.1258/002221503770716232

[25] S. Tatsutomi, J. Hurukawa and M. Itoh, "Tonsilla Hypertrophy and Adenoids Vegetations-Their indications," Pediatrics and Internal Medicine, Vol. 40, 2008, p. 1514 (in Japanese).

[26] J. Hibbert and G. H. Whitehouse, "The Assessment of Adenoidal Size by Radiological Means," Clinical Otolaryngology, Vol. 3, No. 1, 1978, pp. 43-47. doi:10.1111/j.1365-2273.1978.tb00664.x

[27] Y. K. Kemaloglu, N. Goksu, E. Inal and N. Akyildiz, "Radioglrphic Evaluation of Children with Nasopharyngeal Obstruction Due to the Adenoid," Annals of Otology, Rhinology, and Laryngology, Vol. 108, No. 1, 1999, pp. 67-72.

[28] Plain Radiographic Evaluation of Children with Obstructive Adenoids, Database on the Internet, 2011.

[29] S. Mukai, C. Mukai, M. Nitta and S. Nagasugi, "The Cause of Nasal Obstruction of the Babies," Annals of Ankyloglossia with Deviation of the Epiglottis and Larynx, Vol. 7, 1997, pp. 29-31 (in Japanese).

[30] S. Mukai, Y. Nose and M. Nitta, "Developmental Alterations on Shape of Choanal Opening and Airflow Rate," Otolaryngology-Head and Neck Surgery (Japan), Vol. 103, 2000, pp. 188-192 (Japanese with English Abstract). 